\title{
Дальние миры в романе Ивана Ефремова Туманность Андромеды
}

\author{
Far away worlds in the novel by Ivan Efremov \\ Andromeda Nebula
}

\begin{abstract}
The characters of the rational utopia by Ivan Efremov feel an irrational attraction to distant worlds. This allows us to reveal the relationship between Efremov's fantasy and the neo-mythological novel of modernism. One of the sources of Efremov's imagery was the book Agni Yoga, published anonymously in Paris by the Roerichs. Nostalgia for the distant worlds becomes a nostalgia for the free world and the pre-revolutionary past of Russia.
\end{abstract}

Keywords: utopia, Efremov, Agni Yoga, modernism, Roerich

Irina Sääsk, University of Tartu, Tartu - Estonia, rina@ut.ee, ORCID ID: https://orcid.org/00000001-6951-3857

В 2017 г. в России отмечалось 60 лет со дня первой публикации романа Ивана Антоновича Ефремова Туманность Андромеды (1957), в котором описывается общество будущего и полеты к дальним мирам. Контакты с межгалактическим союзом Великого Кольца должны были ознаменовать, по мысли автора, новую ступень в эволюции человеческого общества. Идее этой всекосмической связи подчинены все силы человечества в романе.

Однако в момент получения сообщений с далеких планет их отправители уже давно мертвы. Радость от контакта смешивается с горечью утраты и нестерпимой ностальгией по недостижимой внеземной цивилизации. Контакт с космосом - это контакт с прошлым, даже сама карта звездного неба отражает давно минувшее состояние. Не случайно старший современник Ефремова - Илья Эренбург - живой свет потухшей звезды сделал финальным образом своей миниатюрной элегии Умрет садовник, что сажает семя... (1940): 
Фитиль уснет, когда иссякнет масло,

Ветра сотрут ступни горячей след.

Но нежная звезда давно погасла,

И виден мне ее горячий свет.

(Èrenburg 13)

Один из главных героев романа Ефремова, Мвен Мас, совершает рискованный опыт, который ставит под угрозу жизни людей и энергетические запасы всего человечества, чтобы совершить мгновенный прорыв сквозь пространство, настолько сильна в нем тоска по видениям далеких планет, полученным во время сеансов связи. Страстность чувств героев и сама сосредоточенность на теме межпланетного общения представляется несколько чрезмерной для создателя рациональной утопии, каким считается Ефремов. Откуда она берет свои корни? На этот вопрос мы и попытаемся ответить в настоящей работе.

Представление о романе Ефремова как „коммунистической утопии” отчасти верно (Revič 172-212), но требует уточнения. Еще в 1977 г. Леонид Геллер обоснованно поставил советскую ортодоксальность художественного мира Ефремова под сомнение в статье (Geller 134-151). Благодаря исследованию Александры Алексеевны Юферовой, известно, что Ефремов использовал в романе фрагменты книги Агни Йога, анонимно изданной семьей Рерихов в Париже в 1929 г. (Ûferova 40-44). Это - образец религиозно-философской и художественной прозы в духе исканий символизма: синтез науки, искусства и религиозных учений, прежде всего - христианства, буддизма и индуизма. В Советском Союзе подобная литература воспринималась как сугубо враждебная, несмотря на то, что сами Рерихи стремились вернуться в СССР и помочь коммунистам в построении „светлого будущего”.

Активно помогая возвращению рериховского наследия в СССР, Ефремов не считал себя чуждым идее построения коммунизма и успешно обходил идеологические барьеры. Мальчишкой он участвовал в гражданской войне на стороне красных. Служил матросом на Дальнем Востоке, учился в Ленинградском университете, а затем в Горном институте. Стал геологом, доктором биологических наук и профессором палеонтологии. Ефремов создал новую отрасль науки - „тафономию”, за книгу Тафономия и геологическая летопись был удостоен Сталинской премии в 1952 г. Двадцать шесть раз руководил экспедициями, в том числе - в Монголию. С 1942 г. начал писать прозу, документальную, историческую и фантастическую. Его стиль высоко оценил Алексей Николаевич Толстой [недавно Дмитрий Быков в лекции о Ефремове солидаризовался с Толстым: „Ефремов - выдающийся стилист” (Bykov)], но критика писала о нем раздраженно (отчасти потому, что он идеологически неправильно изображал прошлое). 
По признанию Ефремова, роман Туманность Андромеды был написан в пику американской фантастике, в которой господствовала идея „войны миров” (и в подражание роману-утопии Герберта Уэллса Люди как боги) (Efremov I. 1961). Ефремов публично не упоминал об этом, но роман оказался полемичен и по отношению к советской политике изоляции 1940-х годов. К моменту завершения романа в 1956 г., на XX съезде КПСС, было провозглашено „многообразие путей, ведущих к социализму” и взят курс на „мирное сосуществование” с Западом: интенции автора совпали с духом эпохи. В романе Ефремова идея „мирного сосуществования” была выведена на космический уровень: первоначальное название Великое Кольйо символизировало дружбу космических цивилизаций.

Туманность Андромеды - роман о будущем, в котором мир землян преобразился: нет государств, правителей, рас, национальностей, нет частной собственности и семьи в современном понимании. Большая часть населения занята наукой. При этом нет узких специалистов. За время жизни, которая увеличилась в несколько раз, человек сменяет ряд специальностей. Одной из важнейших наук является психология, а одной из важнейших жизненных задач - воспитание: у каждого землянина есть свой личный учитель, которому он дает клятву, приступая к совершению подвигов по достижении совершеннолетия. В этом мире нет насилия: все, кто не хочет жить героической и трудовой жизнью, могут удалиться на острова, где они живут совершенно вольно. На острова удаляются и совершившие преступления. Все вопросы решаются коллективно, общим голосованием-референдумом. Вместо правительства существует система центров управления, связанная между собой по типу нейронной сети мозга.

Сюжет развивается в двух планах: на звездолете „Тантра” и на Земле, которая ищет контактов с другими цивилизациями (одна из важнейших обсерваторий находится в Тибетских Гималаях). В тексте много научных терминов, в том числе Ефремовских неологизмов. Ефремов реформировал жанр утопии, отбросив фигуру внешнего наблюдателя, что компенсируется развернутыми выступлениями-лекциями, обращенными к школьникам и жителям других миров.

В одной из таких речей: в лекции психолога Эвды Наль перед школьниками, приступающими к „подвигам Геркулеса”, - связь с идеями Агни Йоги прослеживается очень четко. Приведем несколько примеров. В 222 Агни Йоги говорится: „Учение, которое ведет к истокам действительности, люди обычно называют мечтами" (Agni Joga 24로. Для Эвды Наль это - в прошлом:

1 Здесь и далее - цитаты приводятся по изданию Учение Живой Этики: Знаки Агни Йоги (см. Библиографию) с указанием в скобках Agni Joga. 
„Когда-то люди называли мечтами стремление к познанию действительности [...]” (Efremov I. 1976: 204). В § 32 дается установка: „Нет личного желания, но непреложность законов материи. Не хочу, но - знаю" (Agni Joga 32). В эпоху Эвды Наль это общепринятая норма: „Когда мы говорим «Хочу», мы подразумеваем: «Знаю...»” (Efremov I. 1976: 204). В § 163 содержится утешение: „Не обращайте внимания на ныряния и взлеты духа, ибо это могут быть лишь кольца спирали движения" (Agni Joga 104-105). Эвда Наль вторит: „Не обращайте внимания на спады после взлетов души, потому что это такие же закономерные повороты спирали движения, как и во всей остальной материи" (Efremov I. 1976: 204).

Нет возможности описать философию Агни Йоги (буквально: огненной йоги или огненной связи), тем более, что ее полное изложение содержится в четырнадцати книгах, о существовании которых Ефремов и не знал до середины 1960-х годов. В ее русском названии Живая Этика отражен развивающийся характер учения. Сложный метафорический стиль и фрагментарная композиция (унаследованная от структуры дневниковых записей) делают текст герметичным, закрытым для неподготовленного читателя.

Ефремовское понимание этого учения отразилось в письме врачу Василию Вячеславовичу Россихину от 6 марта 1971 г.:

Путь в наше время лежит через общественную йогу (агни-йогу) - самоусовершенствование, и самоограничение. Но в иных целях, чем в личной йоге, которой начинают увлекаться, мечтая получить особую власть и силу. Если бы они знали, что не получат ничего, кроме самопожертвования и долга. На самых высших ступенях „посвящения” человек не может жить, не борясь с окружающим страданием, иначе он погибнет (Eremina 1276).

В книге Агни Йога раскрываются важнейшие понятия и образы, актуальные и для Туманности Андромеды: ученичество, героический труд, подвиг, борьба света и тьмы, научный прогресс, межпланетные полеты, эволюция и „новый” мир. Агни Йога также содержит своеобразный футурологический проект. Как и многие символисты, Рерихи ожидали, что сощиальная революция станет революцией духа.

При этом многие ключевые понятия советской идеологии также находили своеобразные параллели в учении Живой Этики. Например, героический „труд” в книге Агни Йога является одним из центральных понятий, и в ссылке репрессированные участники рериховских кружков довоенной Прибалтики проявляли чудеса трудолюбия, искренне веря, что они строят „новый мир" (см. Karklinâ).

Мы уже отметили, что выход романа счастливо совпал с эпохой Оттепели. Но без критики не обошлось. Рецензентов настораживало отсутствие упоминаний классиков марксизма-ленинизма и Октябрьской революции 
(слова „советский” нет вообще). По воспоминаниям сына писателя, Ефремов отказался упоминать статую Ленина в Туманности Андромеды, несмотря на то, что ему предлагали за это Ленинскую премию. Аллан Ефремов вспоминал: „Например, ему прямо намекали, что если он в «Туманности Андромеды» поставит на площади памятник Ленину, то он получит Ленинскую премию" (Efremov А. 1998: 23-28).

Успеху, однако, способствовало то, что роман был опубликован в год запуска первого искусственного спутника земли. Он сразу стал „культовым”. И через десять лет был экранизирован. Первая публикация резко повысила тиражи и рейтинг журнала „Техника молодежи”. Книга переиздавалась больше ста раз на русском и других языках. В 1960 г. на книжной ярмарке в Париже роман Ефремова, переведенный на французский, оказался самой продаваемой русской книгой. Очередной корейский перевод вышел в 2017 г.

На критику Ефремов отчасти ответил в своей статье На пути к роману „Туманность Андромедьљ, которая вышла в журнале „Вопросы литературы” как раз к моменту полета Юрия Гагарина. Разумеется, он ни словом не упомянул запрещенных источников своего романа. И речь идет не только об Агни Йоге. Забыв про классиков марксизма-ленинизма, он цитирует стихи Максимилаина Волошина и Эдгара По в переводе Константина Бальмонта.

Только в конце 1957 г. с приездом в Москву Юрия Николаевича Рериха, приглашенного лично Никитой Хрущевым восстанавливать советское востоковедение, имя Рериха начинает освобождаться из-под гнета запретов. С 1958 г. в СССР начинают проводиться рериховские мероприятия: выставки картин, доклады, публикации, снимается документальный фильм. Вокруг Юрия Рериха складывается кружок молодых ученых и единомышленников, среди которых и будущие „семиотики” Владимир Николаевич Топоров и Александр Михайлович Пятигорский. Завязалась дружба и у Рериха с Ефремовым.

В 1963 г., закончив Лезвие бритвы, Ефремов приступил к работе над продолжением Туманности Андромеды - романом Час Быка. И вновь ему потребовалась рериховская литература. В 1965 г. Ефремов обращается к Святославу Николаевичу Рериху с просьбой прислать из Индии книги. Святослав Рерих посоветовал обратиться к знатоку и собирателю наследия Рерихов из Эстонии - Павлу Федоровичу Беликову (1911-1982). Между Беликовым и Ефремовым завязалась теснейшая дружба. Беликов присылал Ефремову редкие и запрещенные книги, а Ефремов распространял их самиздатом с помощью своего друга Георгия Константиновича Портнягина (брата одного из сотрудников Николая Константиновича Рериха).

В свою очередь Ефремов всячески поддерживал Беликова: он смог успешно провести переговоры с издательством „Молодая гвардия” о публи- 
кации книги „Рерих” в серии „ЖЗЛ”. Книга Беликова, написанная в соавторстве с Валентиной Павловной Князевой, появилась за два года до 100-летнего юбилея художника в 1972 г. Ефремов успел прочитать ее перед смертью и поздравить Беликова с победой. И по сей день, несмотря на все жертвы, принесенные цензуре, беликовская биография считается классикой рериховедения и переиздается на разных языках.

Ефремов цитировал не только Рерихов, но и Гумилева, Волошина, Сологуба, Цветаеву, Шкапскую, однако в романах о будущем имен не упоминал, умело маскируя „несоветское” под „советское”, а по сути - скрещивая коммунистический идеал с идеями Агни Йоги, то есть осуществляя именно то, чего хотел, но не мог реализовать сам Рерих. В качестве примера того, как рериховский текст у Ефремова безупречно „кодируется” советским кодом, можно привести ефремовскую трансформацию „молитвы Шамбале” из книги Агни Йога.

Шамбала - мифическая страна, место пребывания бессмертных Учителей. То есть „молитва Шамбале” - это молитва учителям. Поскольку общение с бессмертными Учителями происходит через земного учителя, обращение в молитве оформлено в единственном числе (§ 104): „Ты, Позвавший меня на путь труда, прими умение и желание мое. Прими труд мой, Владыка, ибо видишь меня среди дня и ночи. Яви, Владыка, руку Твою, ибо тьма велика. Иду за Тобою! ” (Agni Joga 67). В книге молитва превращена в „Клятву Геркулеса”, которую дают совершеннолетние перед подвигами Геркулеса: „Вы, Старшие, позвавшие меня на путь труда, примите мое умение и желание, примите мой труд и учите меня среди дня и среди ночи. Дайте мне руку помощи, ибо труден путь, и я пойду за вами" (Efremov I. 1976: 202). Эту клятву цитирует в своей лекции Эвда Наль.

В фильме Евгения Шерстобитова и Владимира Дмитревского (первоначальный сценарий написан самим Ефремовым) эта клятва не просто упоминается, а звучит в общей сложности не менее пяти раз, начиная с начала фильма. Не вызывая при этом у зрителей никакой настороженности. 23 ноября 1968 г. востоковед Георгий Пермяков сообщал Ефремову о реакции кинозала:

Но вот я сижу на Андромеде. Интересно, будет она лучше книги или хуже? В зале молодые люди, дело было днём. Начинается картина с пионерского собрания (сбора), как думают все, но, оказывается, это передача эстафеты. Начало не из увлекательных. Сам роман начинается по-другому и сразу захватывает (Eremina 998).

Многие зрители восприняли клятву Геркулеса как пионерскую, хотя между ними почти нет лексических совпадений. Идентичны слова „учить”, „я” и союз „и”. Примечательно, что заглавный символ фильма - рука, несущая 
огонь знания, не имея прямой аналогии в романе, отчетливо перекликается с диптихом Николая Рериха Агни Йога (1928-1930). То, что было Ефремовым завуалировано: „Дайте мне руку помощи, ибо труден путь”, - вернулось на визуальном уровне к исходной формуле: „Яви, Владыка, руку Твою, ибо тьма велика” (Agni Yoga 67). Конечно, и этот „,рериховский” элемент был воспринят аудиторией как вполне „советский”, что полностью отвечало замыслу писателя.

Ефремов не стремился отказаться от слова „коммунизм”. Он только хотел наполнить его иным содержанием - в полном согласии с Агни Йогой, которая советовала не „влезать на костер”: „Задача была дать не запрещенную, но зовущую формулу" (Agni Joga 18). Той же стратегии Ефремов придерживался и в романе Чac Быка, который смог выйти в 1968 г., в год Пражской весны и усиления цензуры. Но с появлением книжной версии романа в 1970 г. он был негласно запрещен, а после смерти писателя в 1972 г. дом Ефремова был подвергнут многочасовому обыску.

В Агни Йоге около 80 раз упоминаются „дальние миры” и неоднократно - планеты и межпланетные сообщения. Уже в самом начале утверждается: „Только при устремлении к междупланетности можно рассчитывать на эволюцию человечества” (Agni Joga 13). Цель учения формулируется так: „Изучение Агни-Йоги приближает человека к дальним мирам [...] Сознательная борьба доводит подвижника до исполнения задачи [...] он выводит планету из одиночества” (Agni Joga 107-108). Ср.: „Даже день трудно пробыть без воды; так же тяжко нашему сознанию пребывать без освещения дальними мирами” (Agni Joga 252); „Явленная череда Учителей сияет жемчугом междупланетным” (Agni Joga 58); „Стремление к дальним мирам есть естественное направление человеческого духа, вспоминающего свои междупланетные опыты. Необходимо направить человечество на путь к дальним мирам" (Agni Joga 86-87).

Однако в книге не описаны полеты на космических кораблях: „Йог не улетает в заоблачные страны, но держит серебряную нить связи дальних миров” (Agni Joga 121); „Для йога каждая нить сознания будет нитью дальних миров” (Agni Joga 142). Оказывается, „можно в ментале посещать разные планеты” (Agni Joga 12). Именно по этому пути в романе Ефремова пытались пойти Рен Боз и Мвен Мас. Правда, они все равно использовали возможности техники.

В Агни Йоге связь миров описывается иначе: есть особые состояния сознания, через которые осуществляются контакты, они обозначены символически как ритм, музыка и огонь: „[...] ритм составляет сущность музыки сфер. [...] Качество чистоты звуков является междупланетным проводом" (Agni Joga 97); „Огонь [...] явится надёжным проводником в дальние миры” 
(Agni Joga 102); (§ 530) „Когда станут слышны звуки с дальних миров? Может быть каждый день, ибо внутренний огонь готов и соединение может произойти" (Agni Joga 324).

Правда, авторы книги предвидят и способы физического контакта: „Изучение общения между мирами должно пойти по каналам магнитных волн" (Agni Joga 50-51). Но в Агни Йоге этот способ не является основным. Главное - вывести планету из космического одиночества, и этой задаче посвящают себя герои Ефремова.

Случай Ефремова хорошо иллюстрирует известное положение о том, что в культуре ничто не проходит бесследно, и то, что доминировало в одну эпоху, может сохраняться позднее на периферии литературного поля. Советская фантастика сохранила некоторые элементы культуры модернизма и неомифологического романа начала XX века. „Коммунистический идеал” советского человека был внутренне неоднороден и во многих случаях носил черты своеобразного „двоеверия”. Это, по-видимому, и придавало ему определенный запас прочности, позволяя многим понимать его по-своему, зачастую в гораздо более гуманном и дифференцированном ключе, нежели требовала официальная идеология.

\section{Библиография}

Bykov, Dmitrij. Odin. Vremâ vyhoda v èfir: 15.04.2016, 00:05. Web. 22.03.2020. http://echo.msk. ru/programs/odin/1747344-echo/.

Efremov, Allan. „Vospominaniâ ob otce”. Materialy 1-go Meždunarodnogo simpoziuma Ivan Efremov - učenyj, myslitel', pisatel'. Vzglâd v 3-e tysâčeletie. Predvideniâ i prognozy. Red. Larisa Mihajlova, Tat'âna Korablëva. Moskva, НЭЦ „ЭОЛ”, 1998.

Efremov, Ivan. „Na puti k romanu Tumannost' Andromedy”. Voprosy literatury, nr 4, 1961, s. 142-153. Efremov, Ivan. Sočineniâ: $v$ t. T. 3, kn. 2. Moskva, Molodaâ gvardiâ, 1976.

Eremina, Ol'ga, red. Perepiska Ivana Antonoviča Efremova. Moskva, Veče, 2016.

Èrenburg, Il'â. Stihotvoreniâ. Moskva, Sovetskaâ Rossiâ, 1982, s. 153.

Geller, Leonid. „Mirozdanie Ivana Efremova”. Vremâ i my, nr 24, 1977, s. 134-151.

Karklinâ, Inga-Galina. Kapli živoj vody. Samara, Agni, 1997.

Revič, Vsevolod. Perekrestok utopij. Sud'by fantastiki na fone sudeb strany. Moskva, Institut vostokovedeniâ Rossijskoj Akademii Nauk, 1998, s. 161-197.

Učenie Živoj Ėtiki: Znaki Agni Jogi. Moskva, Meždunarodnyj centr Rerihov, 1994.

Ûferova, Aleksandra. „Ivan Efremov i Agni Joga”. Nauka i religiâ, nr 4, 1991. 